\title{
Thoughts on Supervision over Biopharmaceuticals in China
}

\author{
Dehua Yang \\ Faculty of Business Administration, Shenyang Pharmaceutical University \\ Shenyang 110016, Liaoning, China \\ Shanxi Vocational and Technical College of Biological Applications \\ Taiyuan 030031, Shanxi, China \\ E-mail: ydh1999656@126.com \\ Li Dong \& Juan Liu \\ Faculty of Business Administration, Shenyang Pharmaceutical University \\ Shenyang 110016, Liaoning, China
}

\begin{abstract}
In view of the present situation of China's biopharmaceutical industry and by analyzing the status quo of supervision in the fields of bio-pharmaceutical registration, production and circulation, this text tries to propose some appropriate measures for improvement. And some conclusions are made that supervision over biopharmaceutical industry must be continually improved; measures should be made by the State Food and Drug Administration to make the biopharmaceutical industry have a sound development.
\end{abstract}

Keywords: Biopharmaceutical, Present situation, Supervision, Suggestion

Bio-pharmaceutical industry is one of the most promising industries. The rapid development of biotechnology has produced a profound impact on human society. In recent years, gene technology, biology, bio-chips and transgenic technology, and the development of bio-medical technology have led to the rapid development of bio-pharmaceutical industry. The biopharmaceuticals has played an important role in promoting the social and economic development.

\section{The present situation of the biopharmaceutical industry in China}

Biopharmaceutical industry has greatest potential of development. The rapid growth of biotechnology has produced deep effects on the human society. Recently, gene technology, biology, biochip, transgenic technology and other biopharmaceutical technologies' development has brought along the rapid growth of biopharmaceutical industry. The biopharmaceutical helps to give a push to the social economy and development.

\subsection{The characteristics of the biopharmaceutical industry}

Biopharmaceutical industry is a high-tech industry with large investment, big risk but great profits. As a newly emerging industry, it is knowledge-intensive with high technology content, close cooperation and integration or penetration of many disciplines. Great amounts of money must be invested to build GMP and the cleanliness of the production environment is much more rigid than other ordinary drugs. There are uncertainties in every stage of producing biological medicine and any small failure of any link will result in the collapse of the whole. However, all the investment can be restored in two or three years after the biological medicine is promoted into the market and the rate of market return is extremely high.

\subsection{The output value of the biopharmaceutical industry in China in recent years}

Although research on biotechnological drugs in China started late, it has attracted more attention from the Chinese government. In June 2009, the office of the State Council issued Several Policies of Accelerating the Development of Bio-industry in China and pointed out that the biopharmaceutical field is the vital one for the development of modern biotechnology. (Note 1) According to National Development and Reform Commission, the central government has arranged 442 million Yuan to support the special construction of bio-medicine, bio-breeding, and bio-medical engineering. (Note 2) 
After many years of development, the bio-medicine of China has obtained a very good foundation. The following is the status quo of China's biological and biochemical manufacturing sectors in recent years. The data show that China's bio-pharmaceutical industry has appeared a tendency of growth.

\section{Insert Table 1 and Table 2 Here}

\subsection{The status quo of the main biopharmaceutical products in China}

When the traditional Chinese medicine and the chemical drugs can not cure cancers, AIDS, hemophilia, and rare genetic diseases, the biopharmaceutical drugs have began to appear a promising market. Biopharmaceutical developments are mainly concentrated in several ways against diseases of tumor, neurodegenerative, autoimmune and coronary, and in studying and developing the blood substitutes.

\subsubsection{Blood products}

Of the current blood products, human albumin and human serum globulin are the dominant ones. However, China has low consumption capacity and there are relatively products of surplus. And the massive influx of imported products has given a great effect on this industry. Due to the intense market competition, some manufacturers resort to illegal means to reduce cost. In China, several products extracted from plasma have low comprehensive utilization. (Note 3)

\subsubsection{Vaccine products}

Market for vaccine products has got a rapid development in China. In 2005, sales volume exceeded 3 billion Yuan with an annual growth rate of about $15 \%$, which was not only higher than the pharmaceutical market growth rate, but also higher than the global vaccine market growth rate. Preventive HB-vaccine made in China accounts for most of the domestic market. Most influenza vaccines are imported because vaccine made in China is backward compared with that in foreign countries in technology, process and stability. Thus it has small market share. (Note 4)

\subsubsection{Recombinant products}

The recombinant protein drugs China can produce are mainly recombinant human interferon, recombinant human erythropoietin, recombinant human granulocyte colony-stimulating factor, recombinant human interleukin and recombinant human growth hormone, etc. Recombinant products are of high technological content, but most of the products made in China are the imitations, indicating the insufficient capacity in exploration and development.

\section{Supervising China's biopharmaceutical industry}

\subsection{The major sectors of supervising the biopharmaceutical industries in China}

After Chinese State Council reformed its institution in 1998, State Drug Administration (SDA) was newly built in charge of the national drug management, supervising the different links of drug development, production, circulation, and adoption administratively and technically. To intensify the supervision, later provincial, city-level and county drug supervision and management administrations have been gradually established. National and provincial drug administrations are responsible for approving the declaration, registration, or certification of drug products while the city-level and county drug administrative departments are mainly in charge of the routine work of supervising the pharmaceutical companies and the production. State Food and Drug Administration (SFDA) is one of the organizations directly under the State Council and is in charge of drug administration and comprehensive supervision of the safety of food, medicine and cosmetics. China has no special biopharmaceutical regulatory administrations. The National Institute for the Control of Pharmaceutical and Biological Products is a direct unit under the State Food and Drug Administration, undertaking the registration and examination of biological products, and the lab work of rechecking the biological products registered. (Note 5)

\subsection{The primary regulations of China's biopharmaceutical supervision}

State Food and Drug Administration, according to legal procedures, has formulated some regulations such as Drug Control Law of the People's Republic of China, Provisions for Drug Registration, Good Clinical Practice, Good Manufacturing Practice, Good Supplying Practice, Provisions for Supervision of Drug Distribution, Measures for the Report and Monitor of Adverse Drug Reaction, Provisions for Prescription and Non-prescription Drug Administration, etc. These regulations involve all the aspects of bio-pharmaceutical registration, production and circulation, etc.

\subsection{The status quo of supervising biopharmaceutical industry in China}

\subsubsection{The status quo of supervising the biopharmaceutical drug registration}

The State Food and Drug Administration is in charge of the national biopharmaceutical registration and management. And the provincial or autonomous regional or municipal food and drug supervision and management departments are authorized by the State Food and Drug Administration to examine the integrity, normative and authenticity of the registration data.

Drug registration management is the starting point for drug supervision. Biopharmaceutical registration must follow the 
Provisions for Drug Administration. The existing Provisions for Drug Administration have been implemented since October 1, 2007. In 2002, a pilot version was introduced and in 2005 it was officially announced. The existing one is based the amendment of 2005. This shows that China's drug registration management has been continuously bettered. Article 6 of the present Provisions for Drug Administration provides that drug registration should follow an open, fair and just principle. State Food and Drug Administration adopts such measures as the chief-examiner collective responsibility system, system of publicity and evading of related personnel, and system of accountability. In addition, acceptance, inspection, review, approval, delivery and other aspects are all under the social supervision. All these have not existed in the previous systems. There are special provisions about biological products in Provisions for Drug Administration. Biological products, or even the generic drugs, must be declared following the procedure of a new drug. Article 11 provides the needed pre-clinical studies of drugs before drug registration is raised, including the synthetic techniques, extraction methods, physical and chemical nature and purity, dosage selection, prescription screening, preparation technology, testing methods, quality indicators, stability, pharmacology, toxicology, and animal pharmacokinetic studies, etc. Biological products are stressed to include the sources of raw materials, quality standards, storage conditions, biological characteristics, genetic stability and immunology research of germ poison species, cell line, and biological tissue, etc. Article 36 provides that applicants can test the clinical drugs in accordance with the sample standard of clinical trials on his their own. They can also entrust a drug control institute according to the law. Vaccine products, blood products, and other biological products regulated by the State Food and Drug Administration must be tested by those drug control institutes appointed by the State Food and Drug Administration. In July 2004, Managerial Methods on Inspection and Approval of Manufactured and Imported Bio-Pharmaceutical Products was formulated. And in October 2005, technological guiding principles such as Technological Guiding Principles of Pre-clinical Protective Vaccine Research, Technological Guiding Principles of Pre-clinical and Clinical Research of Combined Vaccine, Technological Guiding Principles of Quality Control and Clinical Research of Combined Vaccine, Guiding Principles of Grading Standard of Adverse Reaction to Protective Clinical Vaccine have been formulated. Great emphasis in biological products in China can be traced in these regulations.

Provisions for Drug Administration have played an important role in regulating drugs and evaluating biological products. However, in the implementation process some problems appeared of the low standard of rechecking and approving drug registration, resulting in less enthusiasm from the enterprises of creating new drugs. Some so-called new drugs are only renamed on the basis of the original drug by changing dosage form, route of taking medicine, and other irrelevant accessories before they are declared registration of new drugs. These drugs are always renamed to obtain higher pricing after they are promoted into the market. There exist non-standard operations in approval process of drug registration in China. A case in point is that the re-examination of the raw materials, the on-site assessment, and the appraisal process are not publicized. (Zhang, 2009, 28:223)

In addition, China has few research bases for biological drug registration and administration, which are of relatively low professional level. Clinical research abroad is of multi-central, randomized, double-blind, and long-term large-scale study while clinical study in China of the similar size is of small number. Large differences exist in comparison to those abroad in the new clinical methods and application. Some enterprises forged clinical materials, and some checkers are lack of professional abilities and experience. All these have become the potential hazards of China's biopharmaceutical products. (Yang, 2003, pp. 97-99)

\subsubsection{The status quo of supervising biopharmaceutical production}

To ensure the biopharmaceutical quality and safety in the process of production, the biopharmaceutical manufacturing enterprises must be obliged to abide by the Good Manufacturing Practice (GMP). In addition, the State Food and Drug Administration, to further standardize the quality control of biological products, in April 2009, announced that in the process of manufacturing biological products, as to the use of solvents, antibiotics and preservatives, strict regulations are made to determine the batching, sub-granting and batching number. As for specification for drug quality control, there are special requirements for biological products. Penicillin and other high-allergenic drugs should be in an independent workshop with specialized equipment. The processing and filling and storing of toxic species for production or for other purposes, live vaccines and inactivated vaccines, blood products and preventive products must be strictly separated. The acceptance, storage, application and destruction of toxic species of bacteria should abide by the regulations about the storage of microbial trains in China. Since August 2004, Measures for Supervision and Administration of Drug Manufacture has begun to be carried out. It provides that injection, biological products (excluding vaccine products and blood products) and application for inter-provincial commissioned production of drugs are accepted and approved by the State Food and Drug Administration. Vaccine products, blood products and other drugs regulated by the State Food and Drug Administration should not be commissioned to produce. In October 2005, Guiding Principles of Management and Technique Changes in Biological Production, Guiding Principle of Peptide Vaccine Production and Quality Control Technology were formulated. (Note 6)

China's biopharmaceutical enterprises are obliged to pass the GMP certification. However, in this process, some 
companies forged the application materials. Some companies spent a lot of manpower and material resources to meet the requirements of GMP certification. But once they pass the authentication, they go back to what they were again.

Anhui Huayuan Biopharmaceutical Co., Ltd. passed the state authentication in 1999. In June 2006, its clindamycin phosphate glucose injection (Xinfu) had 81 cases of adverse events and caused eleven deaths. Investigation shows that the company's product of Xinfu injection failed to follow the approved parameters of sterilization by lowering the temperature, thus reducing the sterilization effect. The Chinese Drugs and Pharmaceutical Products Verification Institute made the inspection and declared that sterility and pyrogen were not in line with what has been regulated. Bai Yi Pharmaceutical Co., Ltd. of Guangdong passed GMP certification in November 24, 2006. In the drug inspection run by the State Food and Drug Administration, some products of intravenous human immunoglobulin produced in December 2006 could not provide an effective and complete record of production and inspection. And part of the intravenous injections of human immunoglobulin led to positive HCV antibody patients. These events show that there is vulnerability in China's biopharmaceutical regulation of GMP.

\subsubsection{The status quo of supervising bio-pharmaceutical distribution and utilization}

Regulation of drug business requires that retail chain enterprises, wholesale enterprises, large-scale retail enterprises must pass the GSP certification. Before the end of 2004 all pharmacies must comply with the requirements of GSP, or they were not allowed to sell drugs. But in fact, there are still some retailers purchase drugs through unlawful channels, which makes counterfeit and poor quality drugs reach the patients through pharmacies. The pharmacy staff has less professional knowledge about biological products. For instance, vaccines and insulin must be stored in a specific temperature; otherwise, they will lose their activity. Licensed pharmacists are not always there to give a significant instruction for proper drug use. Drug supervisors give a routine test check, which does not fundamentally solve the problem. It seems that licensed pharmacists only exist in name. Biological products are mostly prescription medicine. They are available followed by physicians' prescription. But now people are easy to get any medicine as they like at a drugstore for prescriptions are not needed there, except the special drugs under the special supervision. Proper use of drug can not be guaranteed. And drug abuse does not only waste drug resources, but also causes serious drug resistance.

\section{Suggestions on supervising China's biopharmaceutical industry}

\section{1 renew the regulatory norms in time}

Biopharmaceutical drugs have developed rapidly, but some of China's regulatory laws are behind the times. For example, although Good Manufacturing Practice was released in June 1999, it has still been in use by now. Some provisions do not give specification so there is less operability. Since the Managing Measures of Approving New Biological Products was abolished, there has not appeared a new law or regulation yet.

\subsection{Specialized regulatory agencies over biological drugs should be established}

Biological drugs are special with high risk. Their production, storage, and even the application must be strictly required. FDA of the United States has set up Center for Biologics Evaluation and Research (CBER), whose major task is to assess the non-therapeutic biological products, including approving the registration of blood products and vaccines before they are marketed. China should also establish a special biopharmaceutical regulatory sector to give a professional supervision over the whole process of biological products so as to ensure the safety of biological drugs.

\subsection{Strengthening the routine supervision and management of biopharmaceutical products}

To strengthen the routine supervision over the production and distribution of biopharmaceutical enterprises, a special body should be set up with biopharmaceutical professionals. Attention should not only be paid to examination and approval. It is not all right for those enterprises to pass them. Through supervision and inspection, those biopharmaceutical enterprises dealing with the sale and production of biological drugs will be punished if they are of non-standard quality. Professionals majoring in biological medicine should be arranged to monitor the entire process. (Gao, 2007, pp. 869-870). The supervisors should be trained regularly to improve their professional standards in biopharmaceuticals. (Yan, 2003. pp. 14-15)

\subsection{Special laws concerning licensed pharmacist should be enacted.}

Since 1995 of pharmacist identification and examination, more people have entered the licensed pharmacist team. However, there are actually few people engaged in pharmacy and they can not play the supervisory role over the pharmacies. If law of licensed pharmacist is introduced, licensed pharmacist's status will be enhanced, to some extent, to be able to supervise the pharmacies.

\section{References}

Gao, Tianbing. (2007). On the status quo of China's marketing drug supervision and the countermeasures. Chinese Pharmaceutical Affairs, pp. 869-870.

Yan, Jinyan. (2003). Analyzing the problems in the Drug supervision. Chinese Medicine, pp. 14-15. 
Yang, Yongqi. (2003). Problems in drug supervision and the countermeasures. Journal of Southeast China National Defence Medical Science, pp 97-99.

Zhang, Hui. (2009). Discussing the supervision and management of drug production quality. Heilongjiang Science and Technology Information, p. 223.

\section{Notes}

Note 1. http://www.gov.cn

Note 2. http://guba.hexun.com/000796, guba, 8985246.html

Note 3. in 2008 bio-pharmaceutical industry risk analysis. Beijing Century Future Investment Consulting Co., Ltd., 2007

Note 4. China Industry Development Report. Beijing Economic Information Center Lixin Europe, 2008

Note 5. http://www.sda.gov.cn

Note 6. http://www.sda.gov.cn

Table 1. Earnings of China's biological and biochemical manufacturing industry in recent years

\begin{tabular}{|c|c|c|c|c|c|c|}
\hline Time & $\begin{array}{c}\text { Total output } \\
\text { (million } \\
\text { Yuan) }\end{array}$ & $\begin{array}{c}\text { Increased } \\
\text { by (\%) }\end{array}$ & $\begin{array}{c}\text { Sales income } \\
\text { (Yuan) }\end{array}$ & $\begin{array}{c}\text { Increased by } \\
(\%)\end{array}$ & $\begin{array}{c}\text { Profit } \\
\text { (Yuan) }\end{array}$ & $\begin{array}{c}\text { Increased } \\
\text { by }(\%)\end{array}$ \\
\hline In 2006 & 42247.899 & 21.78 & 39005.512 & 25.5 & 4130.633 & 14.06 \\
\hline $\begin{array}{c}1-11 \text { in } \\
2007\end{array}$ & 47703.454 & 19.92 & 44588.310 & 2.24 & 578.848 & 45.83 \\
\hline $\begin{array}{c}1-11 \text { in } \\
2008\end{array}$ & 69739.747 & 30.86 & 64284.143 & 29.81 & 7688.931 & 21.81 \\
\hline
\end{tabular}

The data are from China Investment Consultant Net.

Table 2. Total output data of pharmaceutical industry from 2002 to 2007

\begin{tabular}{|c|c|c|c|c|c|c|}
\hline Time & 2002 & 2003 & 2004 & 2005 & 2006 & 2007 \\
\hline $\begin{array}{c}\text { Total industrial output } \\
\text { value (billion Yuan) }\end{array}$ & 17.802 & 24.630 & 27.155 & 33.698 & 42.248 & 52.04 \\
\hline $\begin{array}{c}\text { Sales Revenue (million } \\
\text { Yuan) }\end{array}$ & 16.035 & 22.337 & 24.895 & 30.313 & 39.056 & 44.588 \\
\hline
\end{tabular}

The data are from National Bureau of Statistics. 